\title{
HFE gene mutations in Brazilian thalassemic patients
}

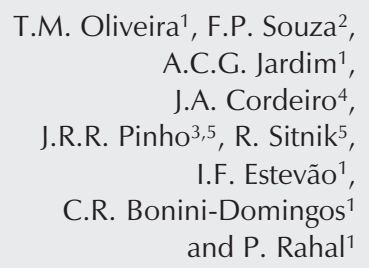

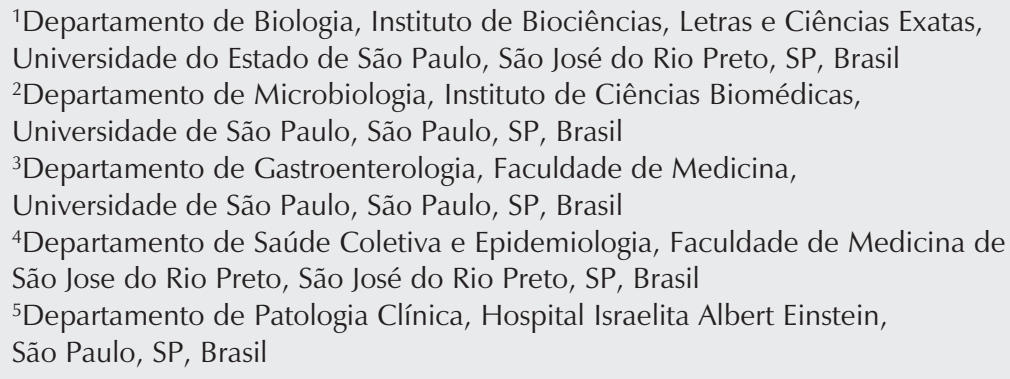

1Departamento de Biologia, Instituto de Biociências, Letras e Ciências Exatas, Universidade do Estado de São Paulo, São José do Rio Preto, SP, Brasil ${ }^{2}$ Departamento de Microbiologia, Instituto de Ciências Biomédicas, Universidade de São Paulo, São Paulo, SP, Brasil ${ }^{3}$ Departamento de Gastroenterologia, Faculdade de Medicina, Universidade de São Paulo, São Paulo, SP, Brasil ${ }^{4}$ Departamento de Saúde Coletiva e Epidemiologia, Faculdade de Medicina de São Jose do Rio Preto, São José do Rio Preto, SP, Brasil ${ }^{5}$ Departamento de Patologia Clínica, Hospital Israelita Albert Einstein, São Paulo, SP, Brasil

Received March 24, 2006 Accepted September 26, 2006

\section{Correspondence \\ P. Rahal \\ Departamento de Biologia Instituto de Biociências, Letras \\ e Ciências Exatas, UNESP \\ 15054-000 São José do Rio Preto, SP \\ Brasil \\ Fax: +55-17-221-2390 \\ E-mail:prahal@ibilce.unesp.br \\ Research supported by $\mathrm{CNPq}$ \\ and FAPESP.}

$\ldots \ldots \ldots \ldots \ldots \ldots \ldots$

\section{Abstract}

Hereditary hemochromatosis is a disorder of iron metabolism characterized by increased iron intake and progressive storage and is related to mutations in the HFE gene. Interactions between thalassemia and hemochromatosis may further increase iron overload. The ethnic background of the Brazilian population is heterogeneous and studies analyzing the simultaneous presence of $H F E$ and thalassemia-related mutations have not been carried out. The aim of this study was to evaluate the prevalence of the H63D, S65C and C282Y mutations in the $H F E$ gene among 102 individuals with alpha-thalassemia and 168 beta-thalassemia heterozygotes and to compare them with 173 control individuals without hemoglobinopathies. The allelic frequencies found in these three groups were $0.98,2.38$, and $0.29 \%$ for the C282Y mutation, 13.72, 13.70, and 9.54\% for the H63D mutation, and 0, 0.60 , and $0.87 \%$ for the S65C mutation, respectively. The chi-square test for multiple independent individuals indicated a significant difference among groups for the $\mathrm{C} 282 \mathrm{Y}$ mutation, which was shown to be significant between the beta-thalassemia heterozygote and the control group by the Fisher exact test $(\mathrm{P}$ value $=0.009)$. The higher frequency of inheritance of the $\mathrm{C} 282 \mathrm{Y}$ mutation in the HFE gene among betathalassemic patients may contribute to worsen the clinical picture of these individuals. In view of the characteristics of the Brazilian population, the present results emphasize the need to screen for HFE mutations in beta-thalassemia carriers.

\section{Introduction}

Iron overload disease can be primary (hereditary) or secondary (inborn or acquired). The latter disorders have in common the fact that the patient is anemic. Primary causes of hemochromatosis usually stem from inherited abnormalities of proteins implicated in
Key words

- HFE

- H63D

- S65C

- $\mathrm{C} 282 \mathrm{Y}$

- Thalassemia iron transport and regulation that may lead to excessive iron absorption from the gastrointestinal tract. Hereditary hemochromatosis $(\mathrm{HH})$ is an iron metabolism disorder characterized by increased iron absorption and storage, resulting in progressive and multisystemic oxidative organ damage (13). In 1996, the $H F E$ gene was identified on 
chromosome 6 and considered to be a candidate for the gene bearing the primary defect responsible for hemochromatosis (3). However, the phenotypic expression of mutated alleles seems to be highly variable and is possibly related to other co-inherited genetic modifiers, including genes related to hereditary anemia $(4,5)$. HH can be the result of defects in the HFE gene (type 1) or to defects not associated with the gene (types $2 \mathrm{~A}, 2 \mathrm{~B}, 3$ and 4). There are 5 major forms of $\mathrm{HH}$ caused by sequence variations in different genes. Classic hemochromatosis is due to variations in the $H F E$ gene.

$\mathrm{HH}$ is most commonly found in Northern European descendants, affecting 1 in 300 persons from this ethnic group $(6,7)$. Three missense mutations in the $H F E$ gene are more frequently associated with $\mathrm{HH}$ and with an autosomal recessive pattern. About $85 \%$ of the patients with HH carry a cysteine-to-tyrosine substitution at amino acid position 282 in the HFE gene (C282Y mutation) (6). This mutation is responsible for $60 \%$ of the $\mathrm{HH}$ cases in the Mediterranean population (8), with a North to South decrease in frequency $(9,10)$. An aspartic acidto-histidine conversion at amino acid 63 (H63D) is widely spread among many populations $(8,11-13)$ and has a frequency of 15$20 \%$ in $\mathrm{HH}$ cases (7). The third mutation results from a serine-to-cysteine conversion in amino acid position 65 (S65C), with an allelic frequency of $1.4 \%$ (14). The last two mutations are associated with milder forms of $\mathrm{HH}(5,15)$, but the compound heterozygous state of one of them and the C282Y defect increase the risk to develop iron overlap especially in men $(15,16)$.

Genetic factors and acquired conditions are likely to modulate the expression of $H F E$ hemochromatosis. Acquired factors, such as dietary habits, blood donation, gender-related events (pregnancy, menopause and mode of contraception), and associated disorders, such as digestive malabsorption or blood loss, have been anecdotally reported to influence phenotypic expression in hemochromatotic subjects but have not been extensively studied. Excess body mass is commonly associated with the lack of phenotypic expression in detected $\mathrm{C} 282 \mathrm{Y}$ homozygotes (17).

The thalassemias are characterized by ineffective erythropoiesis that could induce excess iron absorption and ultimately lead to iron overload $(17,18)$. The thalassemias are a heterogeneous group of hereditary alterations caused by defects in the synthesis of one or more of hemoglobin's polypeptide chains, which modify the normal ratio between the globin subunits, impairing erythropoiesis and, consequently, causing a disturbance in the hemoglobinization of the erythroblasts. The most frequent and defined types of thalassemia are alpha and beta, but other types exist, such as deltabeta-delta and gamma-delta-beta-thalassemia. When anemia is accompanied by increased erythroid activity and/or ineffective erythropoieses there is a concomitant increase in the absorption of iron from the diet because of higher iron needs for hemoglobin synthesis. These patients develop iron overload even without erythrocyte transfusions. If transfusions are needed, they will add to the body iron excess. The interaction of the $\mathrm{HH}$ mutations with the thalassemias may have a synergistic effect, increasing the iron intake and storage $(19,20)$.

The aim of this study was to determine the prevalence of the C282Y, H63D and S65C mutations in the HFE gene of individuals with alpha-thalassemia and betathalassemia heterozygotes and compare it to individuals without hemoglobinopathies.

\section{Material and Methods}

We studied 102 patients with alphathalassemia (69 women and 33 men), 168 patients with the beta-thalassemia trait (96 women and 72 men), and 173 patients without hemoglobinopathies (16 women and 157 
men). All individuals were of Caucasian origin. Blood samples $(5 \mathrm{~mL})$ were collected from individuals from different Brazilian regions (50\% from the Southeast, $25 \%$ from the North, Northeast and West, and 25\% from the South). Screenings for hemoglobinopathies were carried out by the Hemoglobin and Hematological Diseases Laboratory of the University of São Paulo State/ IBILCE, in São José do Rio Preto, SP, Brazil, by HPLC (BioRad, Rio de Janeiro, RJ, Brazil) and by electrophoretic procedures. Ferritin values were in accordance with the expected mean for the alpha-thalassemia group and the control group and slightly increased for the beta-thalassemia group. The hematologic values, indicating hypochromic microcytic anemia in beta-thalassemics, were obtained with automatic equipment and agreed with the clinical evaluation.

The institutional Ethics Committee approved the study and informed written consent was obtained from all patients.

Genomic DNA was extracted from peripheral leukocytes by the phenol-chloroform method (21). Two primer sets were used for DNA amplification. The first, 5'ACATGGTTAAGGCCTGTTGC3' and 5'GCCACATCTGGCTTGAAATT3', generates a 207-bp fragment that comprises the H63D and S65C mutation sites. The second, 5'GGGTATTTCCTTCCTCCAACC3' and 5'CTCAGGCACTCCTCTCAACC3', generates a 441-bp fragment for $\mathrm{C} 282 \mathrm{Y}$ analysis.

The amplified PCR products were digested with the restriction endonucleases BclI (H63D), HinfI (S65C) and RsaI (C282Y). The H63D mutation abolishes the $B c l$ recognition site in the 207-bp PCR product: while normal DNA is cut into two fragments (69 and $138 \mathrm{bp}$ ), the mutated DNA is not cut. The S65C mutation abolishes the HinfI recognition site in the 207-bp PCR product: while normal DNA is cut into two fragments of 60 and $147 \mathrm{bp}$, the mutated DNA is not cut. The C282Y mutation cre- ates a new RsaI site. The digested PCR product is cut into two fragments (145 and $296 \mathrm{bp}$ ) in the normal allele, while in the mutated DNA three fragments $(29,116$, and 296 bp) are generated after digestion. The digestion products of the two first mutations were analyzed on $2.0 \%$ agarose gel stained with ethidium bromide, while the product of the digestion of the $\mathrm{C} 282 \mathrm{Y}$ mutation was analyzed on $2.5 \%$ agarose gel also stained with ethidium bromide.

\section{Statistical analysis}

Data were analyzed by the chi-square test for multiple independent samples to identify the relationship between the mutations and the groups studied. Fisher's exact test was used to compare results between the two groups. A P value $<0.05$ was considered significant.

\section{Results}

Allelic frequencies in the alpha-thalassemic group were $13.72 \%$ for the H63D mutation, $0 \%$ for the S65C mutation and $0.98 \%$ for the C282Y mutation. In the betathalassemic group, mutation frequencies were $13.70 \%$ for $\mathrm{H} 63 \mathrm{D}, 0.60 \%$ for S65C and $2.38 \%$ for C282Y. Finally, in the control group, frequencies were 9.54, 0.87, and $0.29 \%$ for the H63D, S65C and C282Y mutations, respectively (Table 1).

The genotypes found in each group are shown in Table 2. One beta-thalassemic case was a heterozygote for the H63D and S65C

Table 1. Allelic frequencies of the H63D, S65C and C282Y mutations.

\begin{tabular}{lrll}
\hline Subjects & H63D & S65C & C282Y \\
\hline Alpha-thalassemic $(\mathrm{N}=102)$ & $13.72 \%$ & $0.0 \%$ & $0.98 \%$ \\
Beta-thalassemic $(\mathrm{N}=168)$ & $13.70 \%$ & $0.60 \%$ & $2.38 \%$ \\
Controls $(\mathrm{N}=173)$ & $9.54 \%$ & $0.87 \%$ & $0.29 \%$
\end{tabular}

The allelic frequencies were obtained dividing the number of mutated alleles by the total number of alleles. 
mutations, one beta-thalassemic case and one alpha-thalassemic case were heterozygotes for the H63D and C282Y mutations, and three control cases were heterozygotes for the S65C and C282Y mutations. Homozygote mutations were only found for H63D, including 1 alpha-thalassemic and 4 beta-thalassemic patients.

Statistical analysis using the chi-square test for multiple independent samples identified a significant difference for the $\mathrm{C} 282 \mathrm{Y}$ mutation among groups $(\mathrm{P}=0.043)$. Fisher's exact test indicated a statistically significant difference between the beta-thalassemic and control groups $(\mathrm{P}=0.009)$. The H63D and S65C mutations did not show statistically significant differences among the groups studied $(\mathrm{P}>0.05)$.

\section{Discussion}

$\mathrm{HH}$ is considered to be the most common inherited disorder in Caucasians and presents a variable prevalence among different ethnic groups $(2,22)$. Originally regarded as a rare affliction notable for its distinctive evolution to "bronze diabetes", $\mathrm{HH}$ is now recognized as the most common genetic disorder in populations of European ancestry. Recent advances in the understanding of

Table 2. Genotypic frequencies of the H63D, S65C and C282Y mutations.

\begin{tabular}{cccccc}
\hline & Genotypes & & Alpha-thalassemia & Beta-thalassemia & Controls \\
\hline H63D & S65C & C282Y & & & \\
++ & -- & -- & $1(0.98 \%)$ & $4(2.38 \%)$ & $0(0 \%)$ \\
+- & -- & -- & $25(24.51 \%)$ & $36(21.43 \%)$ & $33(19.08 \%)$ \\
+- & +- & -- & $0(0 \%)$ & $1(0.59 \%)$ & $0(0 \%)$ \\
+- & -- & +- & $1(0.98 \%)$ & $1(0.59 \%)$ & $0(0 \%)$ \\
-- & ++ & -- & $0(0 \%)$ & $0(0 \%)$ & $0(0 \%)$ \\
-- & +- & +- & $0(0 \%)$ & $0(0 \%)$ & $3(1.73 \%)$ \\
-- & +- & -- & $0(0 \%)$ & $1(0.59 \%)$ & $0(0 \%)$ \\
-- & -- & +- & $1(0.98 \%)$ & $7(4.17 \%)$ & $1(0.58 \%)$ \\
-- & -- & ++ & $0(0 \%)$ & $0(0 \%)$ & $0(0 \%)$ \\
-- & -- & -- & $74(72.55 \%)$ & $118(70.25 \%)$ & $136(78.61 \%)$ \\
Total & & & $102(100 \%)$ & $168(100 \%)$ & $173(100 \%)$ \\
& & & & &
\end{tabular}

Data are reported as number with percent in parentheses. + = mutated; - = wild. The genotypic frequencies are the percentage of each genotype found in the population studied. iron metabolism, the identification of the gene responsible for hemochromatosis, and extensive epidemiologic studies have changed the diagnostic approach to patients with $\mathrm{HH}$ and other forms of iron overload (23-25). Its phenotypic expression seems to be highly variable and possibly related to several factors, such as availability of iron in the diet, loss of blood associated with menstruation or pregnancy, blood donation, hepatitis, and hemolytic anemia $(9,23)$.

The $\mathrm{C} 282 \mathrm{Y}$ missense mutation is responsible for about $80 \%$ of the cases of $\mathrm{HH}$ at least in Northern European populations. In other areas, e.g., Italy, its frequency is lower and decreases from North to South (9). In Brazil, H63D and C282Y screening in 4 specific populations (Caucasians, African descendants, Parakanã Indians, and a racially mixed group) indicated a low prevalence of the $\mathrm{C} 282 \mathrm{Y}$ mutation (allelic frequency ranging from $0 \%$ for Parakanã Indians to $1.4 \%$ for Caucasian descendants), while the H63D mutation varied from $0 \%$ in Parakanã Indians to $16.3 \%$ in Caucasian descendants (16). The allelic frequencies obtained in the present study for Caucasian individuals were $13.72,13.70$, and $9.54 \%$ for the H63D mutation in the alpha-thalassemia, beta-thalassemia and control groups, respectively. For the $\mathrm{C} 282 \mathrm{Y}$ mutation the frequencies observed were $0.98,2.38$, and $0.29 \%$, respectively, differing from previously published results from Brazil (16).

No data about the S65C mutation have been previously reported in Brazil. The low allelic frequencies observed here $(0.0,0.60$, and $0.87 \%$ for the alpha-thalassemia, betathalassemia and control groups, respectively) agree with data about populations from other geographic areas $(14,24,25)$. A $4.0 \%$ allelic frequency of the $\mathrm{S} 65 \mathrm{C}$ mutation was detected in the Ecuadorian population, one of the highest observed until now (10).

In the present study, some cases of compound heterozygotes were found: one H63D/ $\mathrm{C} 282 \mathrm{Y}$ patient in the alpha-thalassemic 
group, two cases in the beta-thalassemic group (one of them H63D/S65C and the other $\mathrm{H} 63 \mathrm{D} / \mathrm{C} 282 \mathrm{Y}$ ), and three individuals with $\mathrm{S} 65 \mathrm{C} / \mathrm{C} 282 \mathrm{Y}$ in the control group. Compound heterozygosis for $\mathrm{C} 282 \mathrm{Y}$ and $\mathrm{H} 63 \mathrm{D}$ seems to predispose to disease expression (5). The clinical significance of the other forms of compound heterozygosis, such as C282Y and S65C or H63D and S65C, is still controversial (5). However, some of these patients have thalassemia as another factor involving their iron status, which may be responsible for increasing the metal levels.

The clinical observation of a discordant course between individuals with the same hematological alteration (thalassemia) is very common and may be related to the different inherited mutations. Furthermore, the coinheritance of iron metabolism disturbances can lead to an additional overload and an increase of oxidative stress in blood cells, influencing the phenotype expression and the manifestation of additional pathologies. Our findings suggest the need for an early screening for this alteration, especially in Brazil, with its multiethnic characteristics.

In the present study, a high incidence of the $\mathrm{C} 282 \mathrm{Y}$ mutation was observed in the beta-thalassemia group, leading to a concern about the levels of iron deposition in the organism of these patients. Both diseases (hemochromatosis and thalassemia) affect iron metabolism and the meaning of coinheritance of the two mutations is not well understood.

Screening for hemochromatosis mutations in beta-thalassemia minor patients from Iran indicated significant differences in the frequencies of $\mathrm{C} 282 \mathrm{Y}$ and H63D mutants in relation to control individuals (20) but these differences were not observed in Portugal or in India $(26,27)$. Two independent pathways have been proposed for iron metabolism, the erythroid regulator, which modulates intestinal iron absorption in response to the needs of the erythron, and the storage regulator, which controls iron accumulation (28-30).
There are suggestions that the erythroid regulator (beta-thalassemia) seems to be more pronounced than the storage regulator (the mutated HFE gene) in determining the degree of iron absorption $(28,29)$. This hypothesis indicates that beta-thalassemia carriers might exhibit an advantage in balancing iron storage in their organisms. Nevertheless, published data indicate more severe hemochromatosis symptoms when heterozygosis for the $\mathrm{C} 282 \mathrm{Y}$ mutation is associated with beta-thalassemia (19), and when higher serum iron levels in beta-thalassemia co-inheritance are associated with heterozygosis and homozygosis for H63D $(4,26)$. However, these results remain controversial $(29,31)$.

Alpha-thalassemia is a hereditary anemia that results from a defective synthesis of alpha-globin. There are insufficient production of normal hemoglobin and formation of unstable tetramers of $\gamma 4$ ( $\mathrm{Hb}$ Bart's) or $\beta 4$ $(\mathrm{Hb} \mathrm{H})$ with accelerated destruction of the red blood cells. Alpha-thalassemia can be inherited or acquired and is originated by defects or deletions in one or more genes of the four alpha-globin genes. All the current knowledge about alpha-thalassemia, including its molecular biology understanding, was obtained by clinical and laboratory observations. Hypochromic and microcytic cells characterize alpha-thalassemia (32). The $\mathrm{Hb} \mathrm{H}$ and $\mathrm{Hb}$ Bart's are more stable than the alpha-chain aggregates observed in betathalassemia, and do not cause hemolysis. They precipitate in the red blood cells provoking cell damage and premature cell removal from the blood stream by endothelial reticulum systems, reducing the lifetime of the cells. In a study carried out in Hong Kong, iron overload in alpha-thalassemia was not related to hemochromatosis mutations (33). However, more data about the role of HFE mutations in alpha-thalassemic patients are still necessary. Nevertheless, HFE mutations were not found at a higher frequency among Brazilian alpha-thalassemic patients. 
The Brazilian population is a mixture of different ethnic groups and HFE mutations were observed at a higher frequency in beta thalassemic carriers. Hemoglobin chain synthesis disorders and HFE mutations may lead to severely increased iron storage and worsen the clinical picture of hemochromatosis, reinforcing the need for this screening in thalassemic patients in Brazil. This approach may improve a normal life expectancy and the response to specific anemia treatments.

\section{References}

1. Griffiths W, Cox T. Haemochromatosis: novel gene discovery and the molecular pathophysiology of iron metabolism. Hum Mol Genet 2000; 9: 2377-2382.

2. Hash RB. Hereditary hemochromatosis. J Am Board Fam Pract 2001; 14: 266-273.

3. Swinkels DW, Janssen MC, Bergmans J, Marx JJ. Hereditary hemochromatosis: genetic complexity and new diagnostic approaches. Clin Chem 2006; 52: 950-968.

4. Melis MA, Cau M, Deidda F, Barella S, Cao A, Galanello R. H63D mutation in the HFE gene increases iron overload in beta-thalassemia carriers. Haematologica 2002; 87: 242-245.

5. Pietrangelo A. Hereditary hemochromatosis - a new look at an old disease. N Engl J Med 2004; 350: 2383-2397.

6. Brissot P, Guyader D, Loreal O, Laine F, Guillygomarc'h A, Moirand $\mathrm{R}$, et al. Clinical aspects of hemochromatosis. Transfus Sci 2000; 23: $193-200$

7. Vautier G, Olynyk JK. Porphyria cutanea tarda in the HFE-gene and hepatitis C virus era. Am J Gastroenterol 2000; 95: 3350-3352.

8. Candore G, Mantovani V, Balistreri CR, Lio D, Colonna-Romano G, Cerreta $\mathrm{V}$, et al. Frequency of the HFE gene mutations in five Italian populations. Blood Cells Mol Dis 2002; 29: 267-273.

9. Bomford A. Genetics of haemochromatosis. Lancet 2002; 360: 16731681.

10. Leone PE, Gimenez P, Collantes JC, Mino C. Analysis of HFE gene mutations (C282Y, H63D, and $\mathrm{S} 65 \mathrm{C}$ ) in the Ecuadorian population. Ann Hematol 2005; 84: 103-105.

11. Rochette J, Pointon JJ, Fisher CA, Perera G, Arambepola M, Arichchi DS, et al. Multicentric origin of hemochromatosis gene (HFE) mutations. Am J Hum Genet 1999; 64: 1056-1062.

12. Papanikolaou G, Politou M, Terpos E, Fourlemadis S, Sakellaropoulos N, Loukopoulos D. Hereditary hemochromatosis: HFE mutation analysis in Greeks reveals genetic heterogeneity. Blood Cells Mol Dis 2000; 26: 163-168.

13. Campo S, Restuccia T, Villari D, Raffa G, Cucinotta D, Squadrito G, et al. Analysis of haemochromatosis gene mutations in a population from the Mediterranean Basin. Liver 2001; 21: 233-236.

14. Mura C, Raguenes O, Ferec C. HFE mutations analysis in 711 hemochromatosis probands: evidence for $\mathrm{S} 65 \mathrm{C}$ implication in mild form of hemochromatosis. Blood 1999; 93: 2502-2505.

15. Asberg A, Thorstensen K, Hveem K, Bjerve KS. Hereditary hemochromatosis: the clinical significance of the $\mathrm{S} 65 \mathrm{C}$ mutation. Genet Test 2002; 6: 59-62.

16. Agostinho MF, Arruda VR, Basseres DS, Bordin S, Soares MC, Menezes RC, et al. Mutation analysis of the HFE gene in Brazilian populations. Blood Cells Mol Dis 1999; 25: 324-327.

17. Laine $F$, Jouannolle AM, Morcet J, Brigand A, Pouchard M, Lafraise $\mathrm{B}$, et al. Phenotypic expression in detected C282Y homozygous women depends on body mass index. J Hepatol 2005; 43: 1055-
1059

18. Piperno A, Mariani R, Arosio C, Vergani A, Bosio S, Fargion S, et al. Haemochromatosis in patients with beta-thalassaemia trait. $\mathrm{Br} J$ Haematol 2000; 111: 908-914.

19. Rees DC, Singh BM, Luo LY, Wickramasinghe S, Thein SL. Nontransfusional iron overload in thalassemia. Association with hereditary hemochromatosis. Ann N Y Acad Sci 1998; 850: 490-494.

20. Jazayeri M, Bakayev V, Adibi P, Haghighi RF, Zakeri H, Kalantar E, et al. Frequency of HFE gene mutations in Iranian beta-thalassaemia minor patients. Eur J Haematol 2003; 71: 408-411.

21. Sambrook J, Fritsch EF, Maniats T. Molecular cloning: a laboratory manual. 2nd edn. New York: Cold Spring Harbor Laboratory Press; 1989.

22. Brissot P. Hemochromatosis at the intersection of classical medicine and molecular biology. C R Acad Sci III 2001; 324: 795-804.

23. Yen AW, Fancher TL, Bowlus CL. Revisiting hereditary hemochromatosis: current concepts and progress. Am J Med 2006; 119: 391 399.

24. Siah CW, Trinder D, Olynyk JK. Iron overload. Clin Chim Acta 2005; 358: 24-36.

25. Beutler E. Hemochromatosis: genetics and pathophysiology. Annu Rev Med 2006; 57: 331-347.

26. Alexander J, Kowdley KV. Hereditary hemochromatosis: genetics, pathogenesis, and clinical management. Ann Hepatol 2005; 4: 240247.

27. Martins R, Picanco I, Fonseca A, Ferreira L, Rodrigues O, Coelho $\mathrm{M}$, et al. The role of HFE mutations on iron metabolism in betathalassemia carriers. J Hum Genet 2004; 49: 651-655.

28. Levy JE, Montross LK, Andrews NC. Genes that modify the hemochromatosis phenotype in mice. J Clin Invest 2000; 105: 1209-1216.

29. Ajioka RS, Levy JE, Andrews NC, Kushner JP. Regulation of iron absorption in Hfe mutant mice. Blood 2002; 100: 1465-1469.

30. Politou M, Kalotychou V, Pissia M, Rombos Y, Sakellaropoulos N Papanikolaou G. The impact of the mutations of the HFE gene and of the SLC11A3 gene on iron overload in Greek thalassemia intermedia and beta(s)/beta(thal) anemia patients. Haematologica 2004 89: 490-492.

31. Cappellini MD, Fargion SR, Sampietro M, Graziadei G, Fiorelli G. Nontransfusional iron overload in thalassemia intermedia: role of the hemochromatosis allele. Blood 1998; 92: 4479-4480.

32. Higgs DR, Vickers MA, Wilkie AO, Pretorius IM, Jarman AP Weatherall DJ. A review of the molecular genetics of the human alpha-globin gene cluster. Blood 1989; 73: 1081-1104.

33. Chan V, Wong MS, Ooi C, Chen FE, Chim CS, Liang RH, et al. Can defects in transferrin receptor 2 and hereditary hemochromatosis genes account for iron overload in $\mathrm{HbH}$ disease? Blood Cells Mol Dis 2003; 30: 107-111. 